\title{
Point Target Extinction and Scintillation as function of range at LAPTEX, Crete
}

\author{
Arie de Jong, Hans Winkel \\ TNO Physics and Electronics Laboratory \\ PO Box 96864, 2509 JG The Hague, The Netherlands \\ Tel: +31-70-3740456 Fax: +31-70-3280961 E-mail: deJong@fel.tno.nl
}

\begin{abstract}
$\underline{\text { ABSTRACT }}$
The range performance of IRST sensors is partly determined by the propagation of the atmosphere. For low altitude targets the boundary layer of the atmosphere introduces a variety of effects due to inhomogeneities, for which model predictions are not yet well validated. For this reason NATO Research Study Group 5 on "Maritime Infrared Target and Background Signatures, Measurement and Characterization" organized the Low Altitude Point Target EXperiment (LAPTEX) in the Mediterranean Sea at the NATO-FORACS site at Crete (Greece) from 8-26 July 1996.

In this experiment a wide beam point source was mounted on a small ship, sailing out and in along a straight line to the detecting sensors. The same ship was equipped with a comprehensive set of meteorological instrumentation. By determination of the signal decrease with range, propagation models such as LOWTRAN7 can be validated. This concerns the transmission, assuming that the source radiant intensity is known. Of similar importance is the increase of scintillation with range, predicted by other models.

In this paper the setup of the LAPTEX trial is described and the results of some examples of the extinction and scintillation experiments are presented. It is concluded that for the subtropical conditions like at Crete, the LOWTRAN extinction predictions correspond surprisingly well with the measurements. The agreement between the predicted and measured scintillation appears to be less good.
\end{abstract}

Keywords: transmission, IRST, atmospheric boundary layer, scintillation.

\section{INTRODUCTION}

New generation of IR sensors, using focal plane arrays, long linear arrays with time delay and integration (TDI) and larger optics with higher spatial resolution require more knowledge of the atmospheric propagation properties for long ranges $(30 \mathrm{~km}$ horizontal). The most relevant properties concern extinction, scintillation and blurring effects in the midwave (MW, 3-5 $\mu \mathrm{m})$ and long wave (LW, 8-12 $\mu \mathrm{m})$ IR spectral bands.

In the framework of standardizing atmospheric conditions to a set of areas of interest NATO-RSG.5 selected the NATO-FORACS site at Crete for the LAPTEX trial ${ }^{1}$. The most important features of the site are:

- the prevailing wind direction in July is North, determining a true maritime air-stream

- the water depth rapidly increases to $200 \mathrm{~m}$ close to the shore

- the observation heights are relevant for shipborne sensors

- a naval base of the Hellenic Navy is close-by

- the FORACS site is a remote, guarded area, providing free oversea observation directions between $0^{\circ}$ and $120^{\circ}$.

The LAPTEX trial was not only designed for point target detection experiments. According to the terms of reference of RSG.5, the following objectives were defined:

- collect a data set for validation of propagation models such as IRBLEM, MODTRAN, LOWTRAN by means of a low altitude point source

- collect a data set for validation of a range performance model for IRST such as IR Tool

- collect a data set for validation of background radiance and clutter models (sunglints, white caps)

- collect a data set for ship signature models such as SHIPIR

- signature measurement of ships, decoys and aircraft of the Hellenic Navy and Air Force.

Concerning the last objective an investigation was made of the detectability of ships against a rocky coast background and the detectability of small surface targets at short distances ${ }^{2}$ (up to $2 \mathrm{~km}$ ). This paper only deals with the first of the objectives, in which all of the 8 participating nations ( $\mathrm{Ca}, \mathrm{Dk}, \mathrm{Ge}, \mathrm{Gr}, \mathrm{It}, \mathrm{Nl}, \mathrm{UK}, \mathrm{US})$ were interested. The input from Greece was the provision of the platform, carrying meteorological and GPS sensors and variety of sources, all shown in Figure 1, supported by $\mathrm{Ca}, \mathrm{Nl}$ and US. 


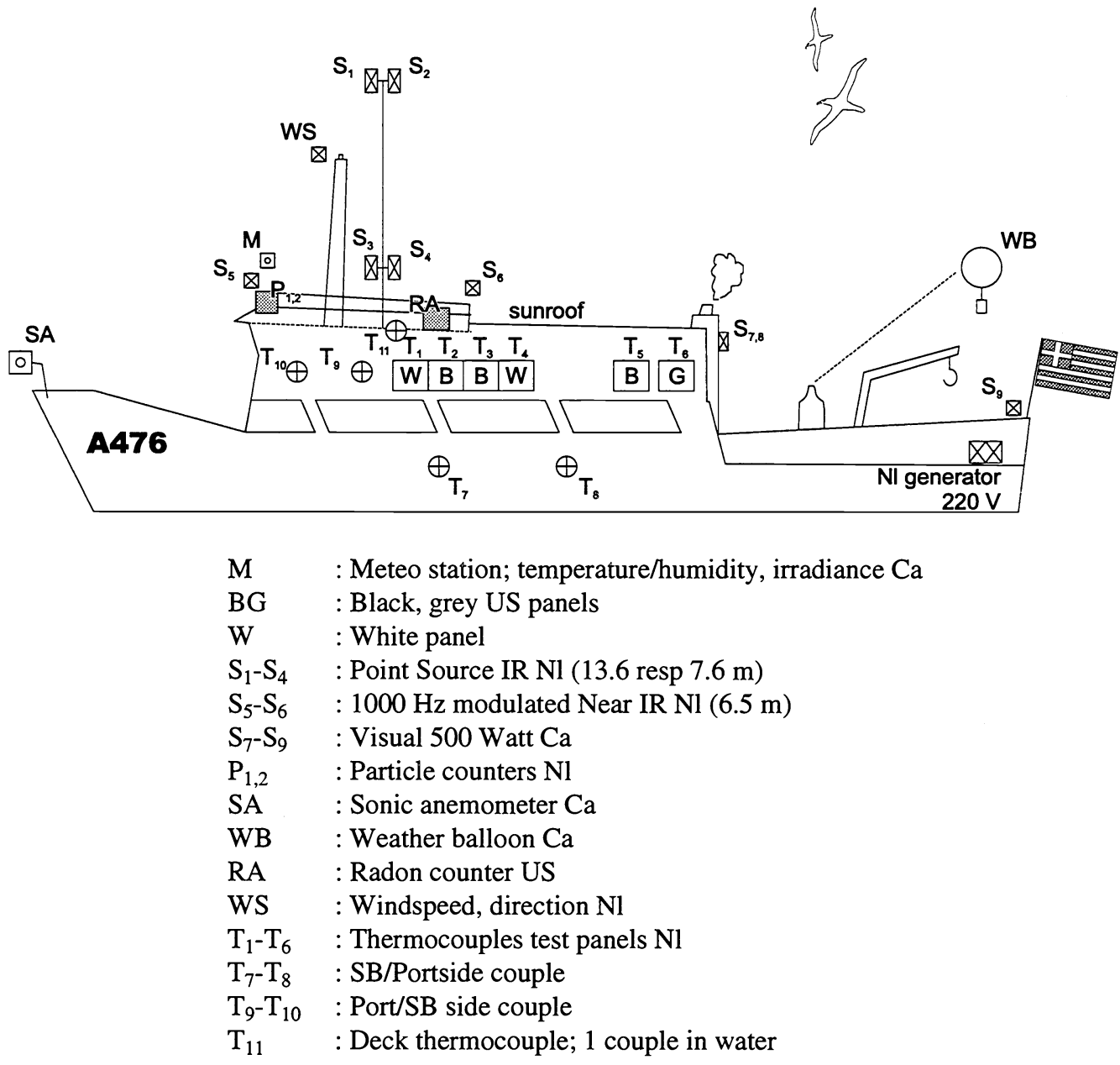

Figure 1: Installation of equipment on board of ship of Hellenic NAVY (ship length $31 \mathrm{~m}$ ).

A set of measurement instruments was installed at various locations at the FORACS site, at various altitudes above the mean sea level. A list with global information on these instruments is given in Table 1. Some of the instruments had a high resolution and great sensitivity like the US-IRSS sensor and Ge: IRRIS256 and CEDIP128 MW resp LW staring sensors. For point target detection the Nl sensors used, were a Cincinnati MW focal plane array (120×160 detectors) and an LW sprite-based USFA imager (UA9092).

As point targets several options have been used:

- helicopters

- jet aircraft

- small propellor plane

- shipborne, calibrated source.

Of these options the slowly moving shipborne point target was the most adequate to carry out and analyse because of the precise knowledge of the range. For the fast jet aircraft a problem was the mountain of Cape Drapano at the back of the FORACS site. An interesting aspect of the site was the presence of sunglint in the morning sessions.

Knowing the average temperature and relative humidity $\left(25^{\circ} \mathrm{C}, 70 \%\right)$, the absolute humidity of $16 \mathrm{~g} / \mathrm{m}^{3}$, being typical for subtropic conditions, allows an estimation of the ranges to be expected for the MW resp LW sensors with given NEI and for a source with given radiant intensity. For MW resp LW radiant intensities of $30 \mathrm{resp} 60 \mathrm{~W} / \mathrm{sr}$ and extinction coefficients of 0.08 resp $0.23 \mathrm{~km}^{-1}$ and NEI values (Noise Equivalent Irradiances) of 1 resp $10 \mathrm{nW} / \mathrm{m}^{2}$ we find detection ranges of $26.7 \mathrm{resp} 10.4 \mathrm{~km}$, taking the LOWTRAN7 predictions and a signal to noise ratio of 5. 
These predictions imply the range at which the source has to be taken out at sea. The longer range allows not only the measurement of extinction as function of range, but also the determination of scintillation. The importance of scintillation in the detection process has been described before ${ }^{3,4}$, from which it is concluded that scintillation may lead to improved detection ranges for sensors with higher frame rate, while low frame rate sensors suffer from scintillation.

Table 1: List of instruments at LAPTEX by nation.

\begin{tabular}{|c|c|c|c|c|c|}
\hline Nation & Sensor & Spectral Band(s) & Frame Rate & IFOV & Use \\
\hline Can & $\begin{array}{l}\text { Visible TV } \\
\text { BOMEM }\end{array}$ & $\begin{array}{l}0.4-0.7 \mu \mathrm{m} \\
3-14\end{array}$ & $\begin{array}{l}50 \mathrm{~Hz} \\
0.1\end{array}$ & $\begin{array}{l}0.01 \mathrm{mrad} \\
0.7 \text { degrees }\end{array}$ & $\begin{array}{l}\text { Refraction effects } \\
\text { Spectrometry }\end{array}$ \\
\hline $\mathrm{Dk}$ & Amber 128 & $3-5$ & 217 & $0.1 \mathrm{mrad}$ & Point target \\
\hline $\mathrm{Ge}$ & $\begin{array}{l}\text { IRRIS } 256 \\
\text { Mitsubishi PtSi } \\
\text { CEDIP } 128 \\
\text { EGG Reticon }\end{array}$ & $\begin{array}{l}3-5 \\
3-5 \\
8-12 \\
0.4-0.7\end{array}$ & $\begin{array}{l}41 \\
50 \\
25-60 \\
1000\end{array}$ & $\begin{array}{l}0.2 \\
0.015 \\
0.2 \\
0.012\end{array}$ & $\begin{array}{l}\text { Point target/ships } \\
\text { Point target } \\
\text { Point target/ships } \\
\text { Scintillation }\end{array}$ \\
\hline It & $\begin{array}{l}\text { HGH } \\
\text { TICM II }\end{array}$ & $\begin{array}{l}0.4-14 \\
8-12\end{array}$ & $\begin{array}{l}16 \\
50\end{array}$ & $\begin{array}{l}1 \text { degree } \\
0.25 \mathrm{mrad}\end{array}$ & $\begin{array}{l}\text { Spectrometry } \\
\text { Point target/ships }\end{array}$ \\
\hline $\mathrm{Nl}$ & $\begin{array}{l}\text { Cincinnati } \\
\text { Transmissometer } \\
\text { Amber } 128 \\
\text { UA } 9092 \\
\text { DUDA } \\
\text { Near IR-Si }\end{array}$ & $\begin{array}{l}3-5 \\
0.85 \\
3-5 \\
8-12 \\
(3-5)+(8-12) \\
0.7-1.0\end{array}$ & $\begin{array}{l}50 \\
1000 \\
50 \\
50 \\
0.25 \\
50\end{array}$ & $\begin{array}{l}0.1 \\
5 \\
0.5 \\
0.2 \\
0.8 \\
0.05\end{array}$ & $\begin{array}{l}\text { Point target } \\
\text { To Strabon source } \\
\text { Ship imagery } \\
\text { Ship/point target } \\
\text { Backgrounds } \\
\text { High resolution clutter }\end{array}$ \\
\hline UK & $\begin{array}{l}\text { AGEMA } 880 \\
\text { TICM II } \\
\text { Radiance I }(2 \times) \\
\text { ADAD (Thorn) }\end{array}$ & $\begin{array}{l}(3-5)+(8-12) \\
8-12 \\
3-5 \\
8-12\end{array}$ & $\begin{array}{l}50 \\
50 \\
50 \\
2\end{array}$ & $\begin{array}{l}1 \\
0.1 \\
0.2 \\
1\end{array}$ & $\begin{array}{l}\text { Ship imagery } \\
\text { Point target } \\
\text { Point target } \\
\text { IRST (point target) }\end{array}$ \\
\hline US & $\begin{array}{l}\text { IRSS } \\
\text { AGEMA } 900\end{array}$ & $\begin{array}{l}(3-5)+(8-12) \\
(3-5)+(8-12)\end{array}$ & $\begin{array}{l}1 \\
15\end{array}$ & $\begin{array}{l}0.1 \\
0.2\end{array}$ & $\begin{array}{l}\text { IRST (point target) } \\
\text { Ship/point target }\end{array}$ \\
\hline
\end{tabular}

\section{SETUP OF THE EXPERIMENT}

The sources $\mathrm{S}_{1}-\mathrm{S}_{4}$ (see Figure 1) were specially made at TNO for IRST sensor testing. The 4 sources were identical, 2 of them forward and 2 backward radiating. Two sources were mounted in a mast at $13.6 \mathrm{~m}$ above mean sea level; two sources were mounted at $7.6 \mathrm{~m}$ above mean sea level. Each source had a wide beam of $54^{\circ}$ (horizontal) $\times 27^{\circ}$ (vertical), an emitting area of $423 \mathrm{~cm}^{2}$ and an apparent temperature of about $1000 \mathrm{~K}$. The size of the encapsulation $(40 \mathrm{~cm})$ is sufficiently small to be considered as a point source for a $0.1 \mathrm{mrad}$ sensor at ranges of more than $5 \mathrm{~km}$. One source, consuming $2 \mathrm{kWatt}$ power (at 220 or $110 \mathrm{Volt}$ ), was switched on at the time.

The source was mounted in a mast in order to be sufficiently separated from other emitting surfaces of the ship. Because of the wide beam of the source, ships motions as pitch and yaw do not affect the received signal too much (max $10 \%)$.

For scintillation measurements the sources $S_{5}$ and $S_{6}$ were mounted at $6.5 \mathrm{~m}$ above mean sea level. The beam width of these sources is about $9^{\circ}$, so the course of the ship had to be pretty precise. The source consists of 18 tungsten lamps, each with $50 \mathrm{Watt}, 12$ Volt power. The radiant intensity is about $750 \mathrm{~W} / \mathrm{ster}$, but as we define scintillation just as the ratio of the fluctuations and the mean received irradiance, the absolute intensity is less important.

More details of the $\mathrm{Nl}$ sensors, as listed in Table 1, but relevant for the experiments described in this paper, are listed in Table 2.

The receiver for the Near IR scintillation measurements contains a silicon detector with Kodak 89B Wratten filter, providing a spectral band from $0.72-1.04 \mu \mathrm{m}$. The receiving aperture is $280 \mathrm{~cm}^{2}$ and the instantaneous field of view $5 \mathrm{mrad}$. Other details are described elsewhere 4 .

The heights of the sources and sensor determine the range at which the source disappears beyond the horizon. As the sensor height was $20.5 \mathrm{~m}$ above mean sea level, the upper source horizon lies at $28.4 \mathrm{~km}$; for the lower source the horizon is at $25.2 \mathrm{~km}$. For this reason the ship was cruising in and out from 5-30 km. With a speed of $10 \mathrm{kts}$ a complete back and forth run takes about $3 \mathrm{hrs}$.

During this time the meteorological conditions can change along the measurement path, as well as at a certain location. In order to have a feeling for this, a simple met-station was installed on a buoy, located at $1100 \mathrm{~m}$ from the shore in direction $030^{\circ}$. The ship passed this buoy at some occasions in order to compare the met-data of the buoy with that of the ship. Connected to the met-buoy 
was a small wave buoy from Canada in order to characterize the wave spectra. It is uncertain however if $1100 \mathrm{~m}$ is far enough from the shore to consider the met-conditions as real maritime. It is realized that the line of sight between source and receiver is passing the atmosphere at variable altitudes when the range is changing. This fact introduces several uncertainties, as the gradients in air temperature, aerosols, turbulence and humidity are the greatest near the sea level. Furthermore the wave structure causes variations in height at locations where the beam is closest to the sea and also the ship is moving up and down, causing a similar effect.

Table 2: List of sensor parameters

\begin{tabular}{|l|l|l|}
\hline Parameter & Midwave & Long wave \\
\hline Spectral band (HMFW) & $3.71-4.59 \mu \mathrm{m}$ & $7.2-10.8 \mu \mathrm{m}$ \\
Field of view & $12 \times 16 \mathrm{mrad}$ & $3^{\circ} \times 5^{\circ}$ \\
IFOV & $0.1 \mathrm{mrad}$ & $0.2 \mathrm{mrad}$ \\
Detector typoe & InSb & HgCdTe \\
No. detectors & $120 \times 160$ & 10 SPRITE \\
Manufacturer & Cincinnati IRC160 & USFA UA9092 \\
Frame rate & $50 \mathrm{~Hz}$ & $50 \mathrm{~Hz}$ \\
Responsivity (DOS) & $3.18 \cdot 10^{14} \mathrm{bits} / \mathrm{W} / \mathrm{cm}^{2}$ & $1.65 \cdot 10^{13} \mathrm{bits} / \mathrm{W} / \mathrm{cm}^{2}$ \\
(Point source) & $(5.5 \mathrm{msec}$ int. time) & $($ at Gain 6$)$ \\
Resp. (ext. source) & $8.6 \mathrm{bits} / \mathrm{degree}$ & $12 \mathrm{bits} / \mathrm{degree}$ \\
NEI & $1.0 \cdot 10^{-14} \mathrm{~W} / \mathrm{cm}^{2}$ & $1.0 \cdot 10^{-12} \mathrm{~W} / \mathrm{cm}^{2}$ \\
\hline
\end{tabular}

\section{METHODOLOGY OF ANALYSIS}

The signal $S(R)$, measured with an IR sensor of a target at range $R$, having a spectral emission $\varepsilon(\lambda)$, can be written as:

$$
S(R)=\frac{C}{R^{2}} \int_{o}^{\infty} \varepsilon(\lambda) \tau(\lambda, R) \rho(\lambda) d \lambda
$$

where $\rho(\lambda)$ is the spectral response of the sensor, $\tau(\lambda, R)$ the spectral transmission of the atmosphere and $\mathrm{C}$ a calibration constant. In order to validate a transmission model, one should take narrow spectral bands, especially in the 3-5 $\mu \mathrm{m}$ window as the atmospheric transmission shows in this window a strong spectral dependence. Narrow bands imply however a low signal to noise ratio and on the other hand IRST sensors generally are wide band.

Unfortunately the source is not a real blackbody one, so calibrations had to be carried out to determine the emission in the 3.7$4.1 \mu \mathrm{m}$ and 4.3-4.6 $\mu \mathrm{m}$ subbands. The LW sensor response starts at $7.2 \mu \mathrm{m}$ where the atmosphere is still opaque at longer ranges. We did these calibrations therefore at the shortest possible ranges with a well defined atmosphere. More details of this procedure are described elsewhere ${ }^{5}$.

What will be compared in this paper is the predicted irradiance $\left(I r r_{p}\right)$ and measured irradiance $\left(I r r_{m}\right)$ multiplied by $\mathrm{R}^{2}$ in order to eliminate the range effect. The predicted irradiance follows from (1) taking $\rho(\lambda)$ flat in the spectral band, given in Table 2 . The measured irradiance follows from the formula:

$$
I r r_{m}=\frac{\operatorname{DOS}(R)}{\text { Responsivity }}
$$

where $\operatorname{DOS}(R)$ is the difference of the sum of all target pixels and the same number of background pixels. The responsivity is obtained in a similar way with a collimator and a standard blackbody source.

Image sequencies are digitally recorded (12 bits), which allows the study of scintillation phenomena by statistical analysis of the series of signal peaks of consecutive frames. Due to the slow speed of the ship, we could grab a considerable amount of data at a large number of ranges. 
Data from the near IR source (1000 Hz modulated) are analyzed by sampling the received signal with $8 \mathrm{KHz}$. The signal to noise ratio is large enough up to ranges of $25 \mathrm{~km}$ (horizon range) in order to subtract the reference signal (by software). After homodyning, the signal is averaged over $10 \mathrm{msec}$, allowing scintillation analysis up to frequencies of $100 \mathrm{~Hz}$.

According to the theory ${ }^{6}$, the magnitude of scintillation will increase with range following the formula:

$$
(S T D / A V G)^{2}=0.496 C_{N}^{2}\left(\frac{2 \pi}{\lambda}\right)^{7 / 6} R^{11 / 6}
$$

where $(S T D / A V G)^{2}$ is the ratio of the standard deviation and the average of the fluctuating signal, $C_{N}^{2}$ the refractive index structure coefficient and $\lambda$ the wavelength. Assumptions in (3) are the homogeneity of the optical properties of the atmosphere over the pathlength including the vertical direction, and a non-saturating scintillation condition. In reality one should know $C_{N}^{2}$ as function of height.

Concerning the measurement of the extinction of the IR signal with range, the data should follow the curves as given in Figure 2 , where the transmittance in the various spectral (sub)bands is given as function of range for a typical Cretan condition, without taking into account any blackbody curve $\left(\int_{\lambda_{1}}^{\lambda_{2}} \tau(\lambda) d \lambda\right.$ for each range).

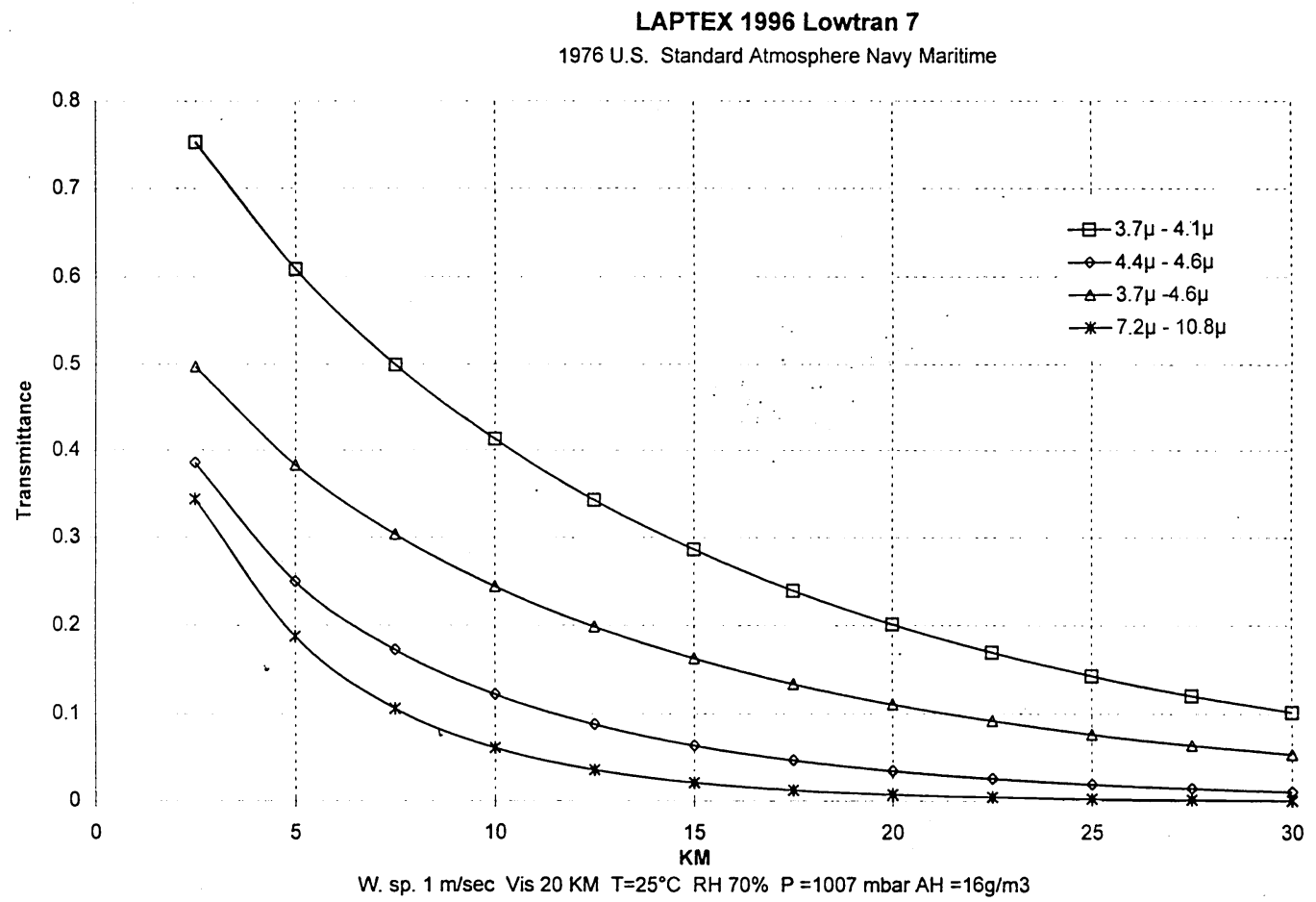

Fig. 2. Transmittance predicted by LOWTRAN7 for typical Cretan condition.

In the calculations a low air mass parameter has been taken due to the fact that the measured particle sizes nicely show a pure maritime size distribution, resulting in very low extinction numbers for the MW and LW spectral band due to aerosols $\left(<0.02 \mathrm{~km}^{-1}\right)$. 


\section{RESULTS}

In total 9 outbound and inbound runs were made with the shipborne point source from the $12^{\text {th }}$ to the $25^{\text {th }}$ of July on various times of the day. Of these 9 sessions, 3 were chosen for more detailed analysis. Data on these 3 sessions are listed in Table 3. During the nighttime sessions of the $17^{\text {th }}$ the ship made an extra long range in-outbound run to obtain more data on the precise horizon range. Table 3 contains weather data of ship and buoy.

Table 3: List of information for 3 selected sessions.

\begin{tabular}{|c|c|c|c|l|l|l|l|l|l|}
\hline \multicolumn{2}{|c|}{} & \multicolumn{3}{c|}{ buoy } & \multicolumn{3}{c|}{ ship } \\
\hline Date & Local time & Course & Range & $\mathrm{T}_{\text {air }}$ & RH & $\mathrm{T}_{\text {sea }}$ & $\mathrm{T}_{\text {air }}$ & RH & $\mathrm{V}_{\text {wind }}$ \\
\hline $17-7$ & 02.13 .03 & $053^{\circ}$ & $4.64 \mathrm{~km}$ & $27^{\circ} \mathrm{C}$ & $42 \%$ & $24^{\circ} \mathrm{C}$ & $25.6^{\circ} \mathrm{C}$ & $66 \%$ & $2.7 \mathrm{~m} / \mathrm{s}$ \\
& 02.43 .03 & 046 & 12.97 & 27 & 42 & 24 & 25.5 & 73 & 4.9 \\
& 03.13 .03 & 052 & 23.26 & 27 & 42 & 24 & 25.2 & 82 & 2.8 \\
& 03.43 .03 & 056 & 33.86 & 27 & 42 & 24 & 24.8 & 92 & 3.5 \\
& 04.13 .03 & 227 & 30.17 & 27 & 42 & 24 & 24.9 & 89 & 3.4 \\
& 04.43 .03 & 049 & 23.67 & 27 & 42 & 24 & 24.9 & 85 & 1.3 \\
& 05.13 .03 & 234 & 29.31 & 27 & 42 & 24 & 25.0 & 87 & 3.4 \\
& 05.43 .03 & 229 & 19.57 & 27 & 42 & 24 & 25.8 & 76 & 3.1 \\
& 06.13 .03 & 232 & 9.47 & 27 & 42 & 24 & 26 & 67 & 4.9 \\
& 19.23 .02 & 026 & 7.81 & 25 & 62 & 25 & 24.7 & 67 & 7.7 \\
& 19.53 .02 & 014 & 16.95 & 25 & 62 & 25 & 24.6 & 67 & 7.0 \\
& 20.23 .02 & 032 & 26.26 & 24 & 62 & 25 & 24.4 & 70 & 5.7 \\
& 20.53 .02 & 207 & 30.22 & 24 & 62 & 25 & 24.3 & 71 & 6.0 \\
& 21.23 .02 & 200 & 19.15 & 24 & 62 & 25 & 24.5 & 67 & 7.2 \\
& 21.53 .02 & 202 & 8.14 & 24 & 62 & 25 & 24.6 & 65 & 5.8 \\
& 08.53 .03 & 058 & 3.19 & 24 & 50 & 24 & 24.5 & 43 & 1.2 \\
& 09.23 .03 & 049 & 13.23 & 24 & 65 & 24 & 23.9 & 69 & 3.0 \\
& 09.53 .03 & 056 & 23.28 & 24 & 65 & 24 & 23.8 & 72 & 5.0 \\
& 10.23 .03 & 052 & 33.47 & 24 & 65 & 24 & 24.0 & 68 & 5.2 \\
& 10.53 .03 & 236 & 22.86 & 24 & 65 & 24 & 23.7 & 68 & 5.7 \\
& 11.23 .03 & 234 & 11.44 & 24 & 65 & 24 & 24.1 & 65 & 4.5 \\
& 11.43 .03 & 230 & 4.10 & 24 & 55 & 24 & 24.1 & 73 & 4.4 \\
\hline
\end{tabular}

MW transmission data for the $17^{\text {th }}$ and $22^{\text {nd }}$ of July are presented in Figure $3 a+b$. The dashed curve in Figure $3 b$ corresponds with the LOWTRAN prediction for low wind speed. The LOWTRAN prediction curves are calculated by means of the formula

$$
W_{\rho_{m}}=I r r_{\rho_{m}} \cdot R^{2}=74 \int_{3.7}^{4.6} e(\lambda) \tau(\lambda, R) d \lambda
$$

where $e(\lambda)$ is the source spectral emission (being 1 at $4.6 \mu \mathrm{m}$ ). So along the vertical axis the apparent radiant intensity is given. Similarly MW and LW measured and predicted data are presented in figure $4 \mathrm{a}, \mathrm{b}$ and $\mathrm{c}$. For the LW prediction we used the formula

$$
W_{\rho_{l}}=I r r_{\rho l} \cdot R^{2}=C_{1} \int_{7.2}^{10.8} e(\lambda) \tau(\lambda, R) d \lambda \text { with } C_{1} \int_{7.2}^{10.8} e(\lambda) d \lambda=66.6 \mathrm{~W} / \mathrm{ster}
$$

for zero range condition.

Figure 5 shows MW scintillation data for 17, 22 and 25 July. For each point in the curve the whole set of 50 recorded images has been used.

Scintillation data, obtained from the $1000 \mathrm{~Hz}$ source are presented as function of range in Figure 6. Examples of the time dependence of the signal and scintillation spectra are presented in Figure 7. 
LAPTEX 17-07-1996 Strabon

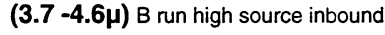

a

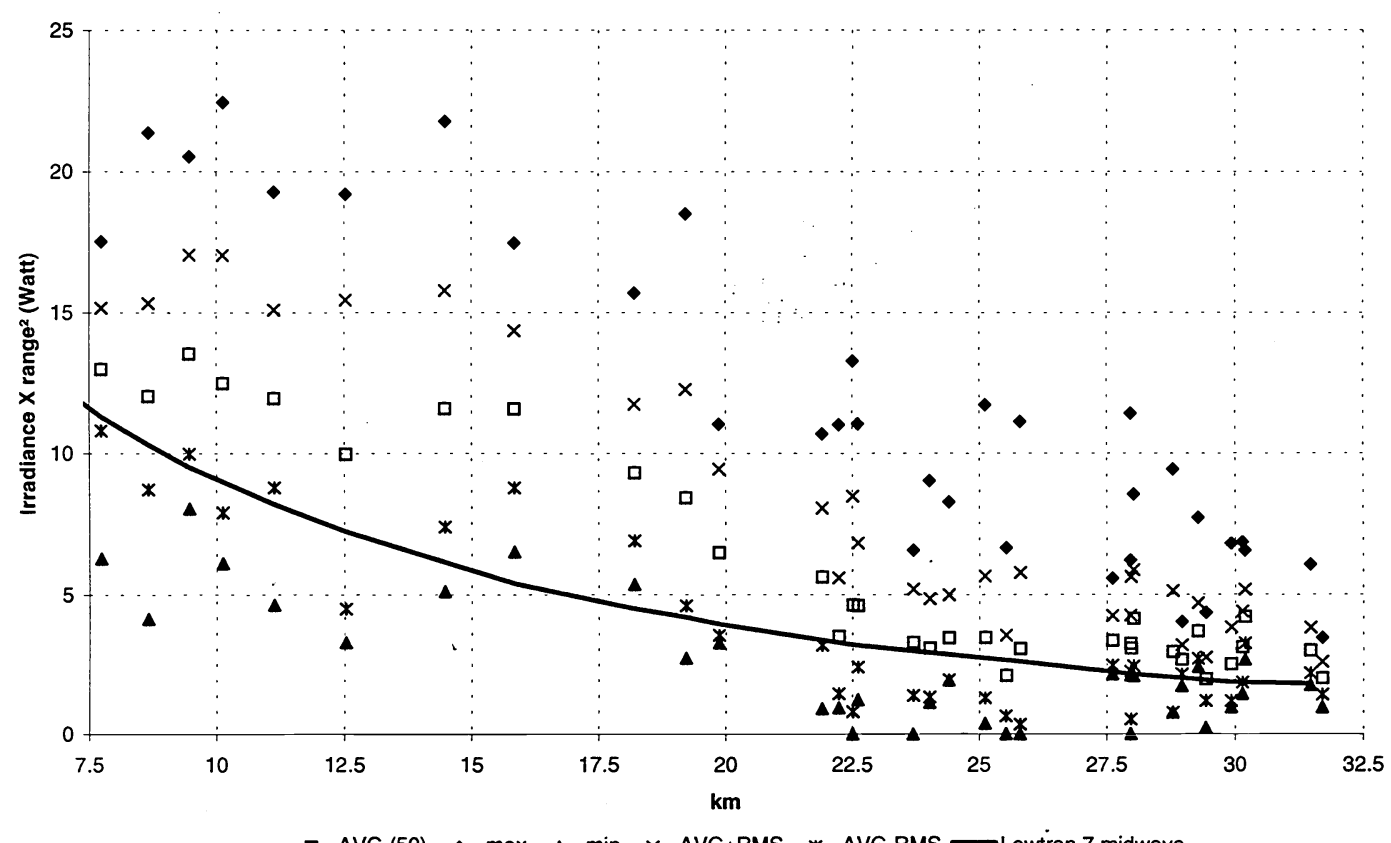

口 AVG (50) $-\max \triangle \min \times$ AVG+RMS $*$ AVG-RMS — Lowtran 7 midwave

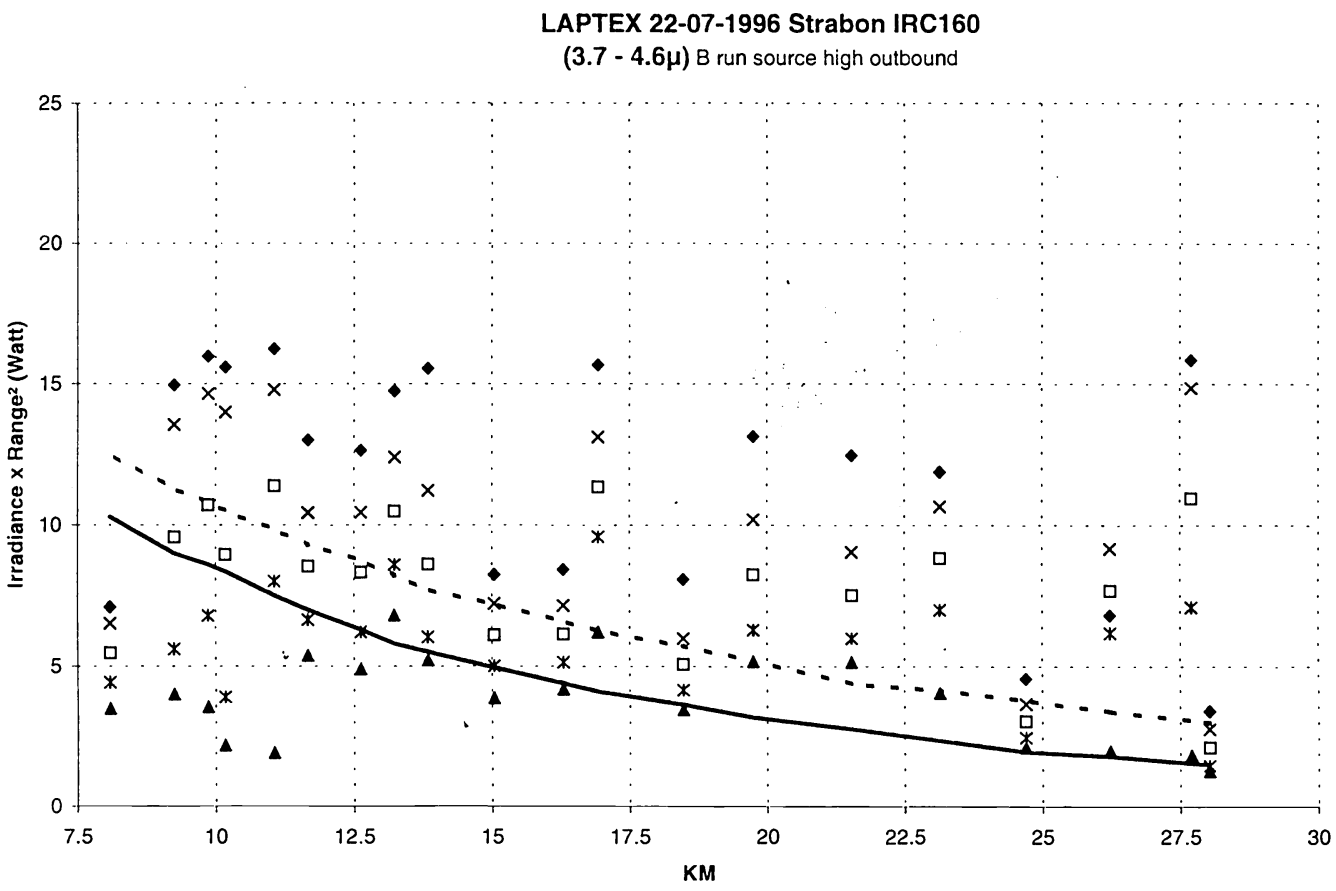

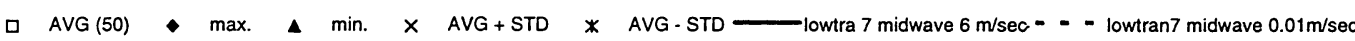

Figure 3: MW results for 17 and 22 July inbound resp outbound runs. 


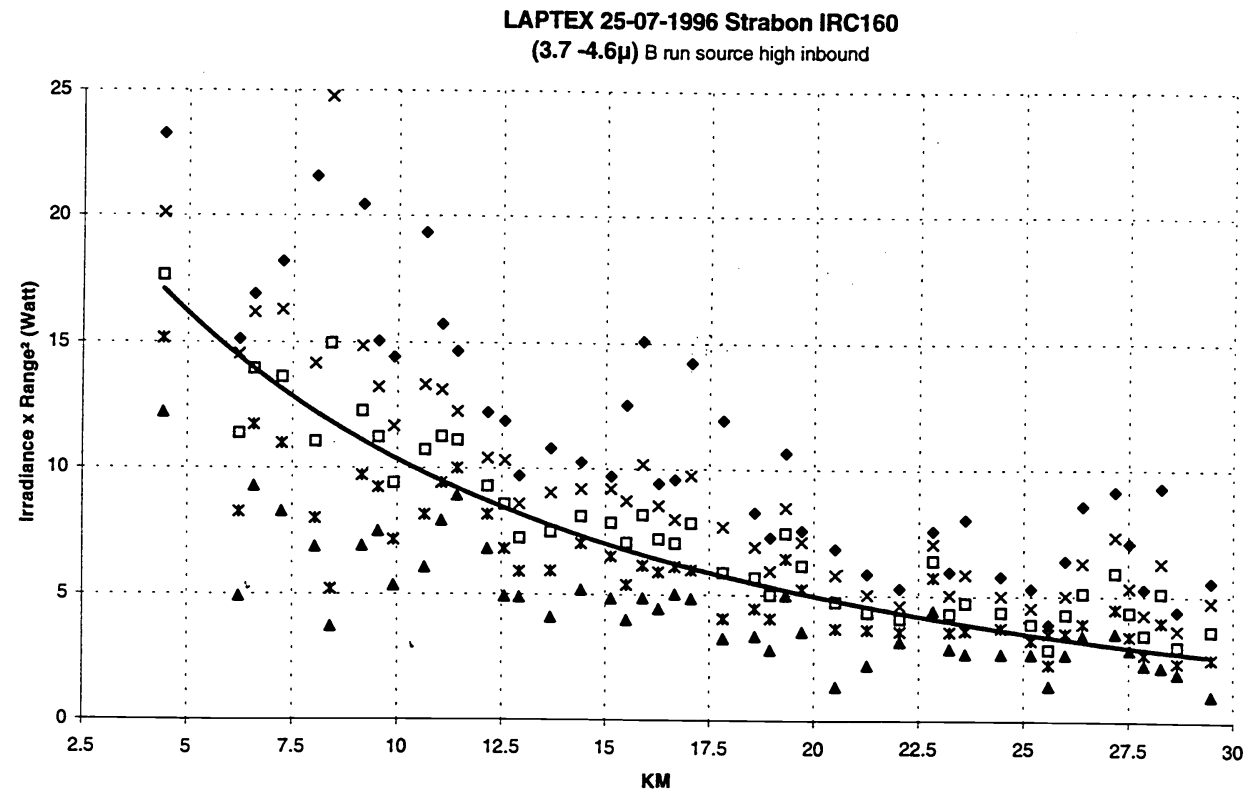

b

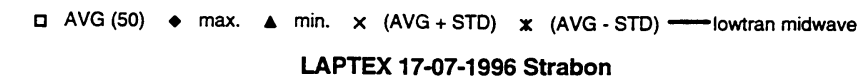

7.2-10.8н B run source high inbound

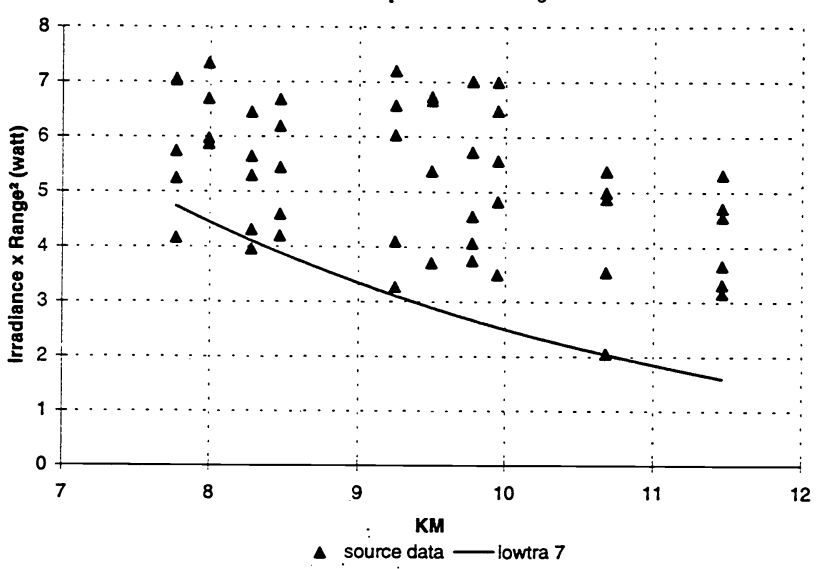

LAPTEX 25-07-1996 Strabon

$7.2-10.8 \mu \mathrm{m} B$ run high source inbound

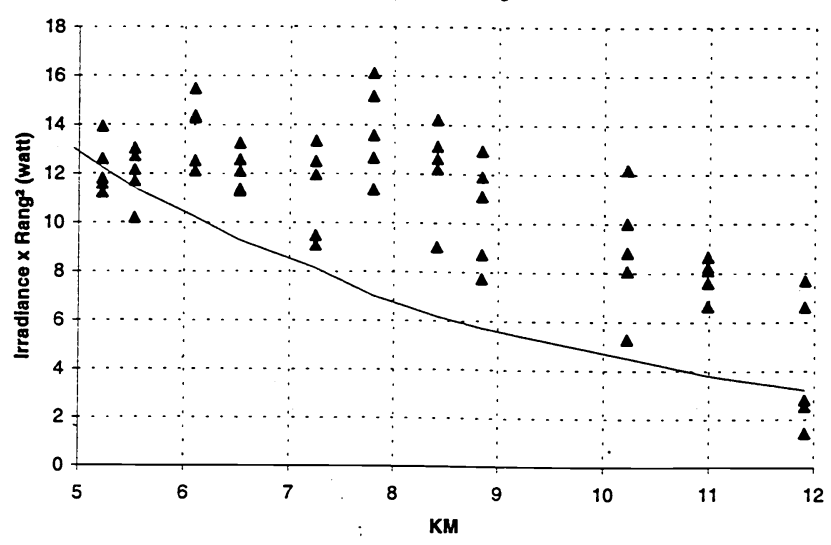

4 source data - lowtran 7

Figure 4: MW and LW results for 17 and 25 July for inbound runs. 
a
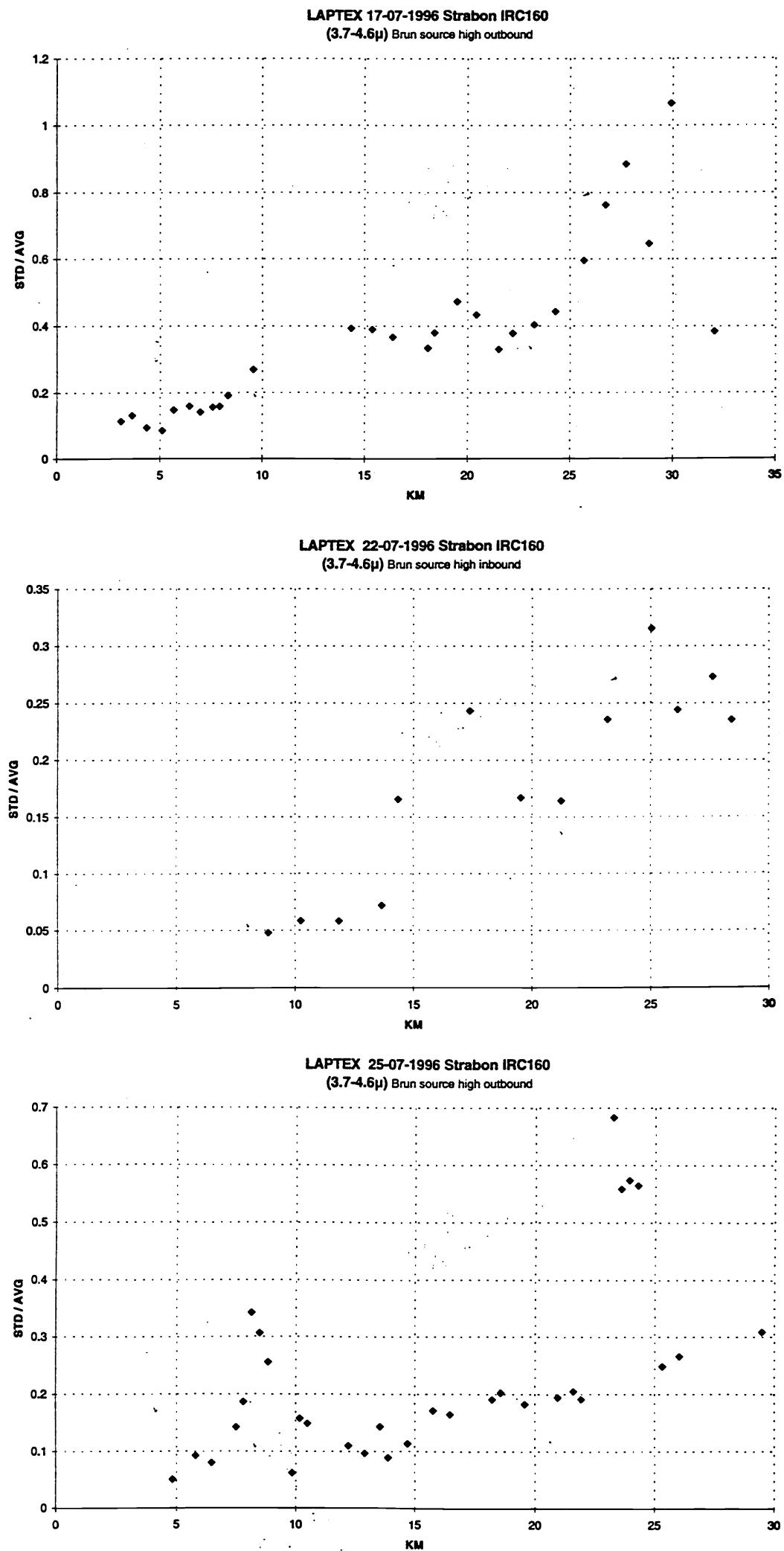

Figure 5: MW scintillation data obtained from IRC160 camera for 17, 22 and 25 July $(S T D / A V G)$ is plotted vs range in km. 


\section{LAPTEX Scintillation 0.85 um \\ Out/In bound run 22 juli 1996}

a

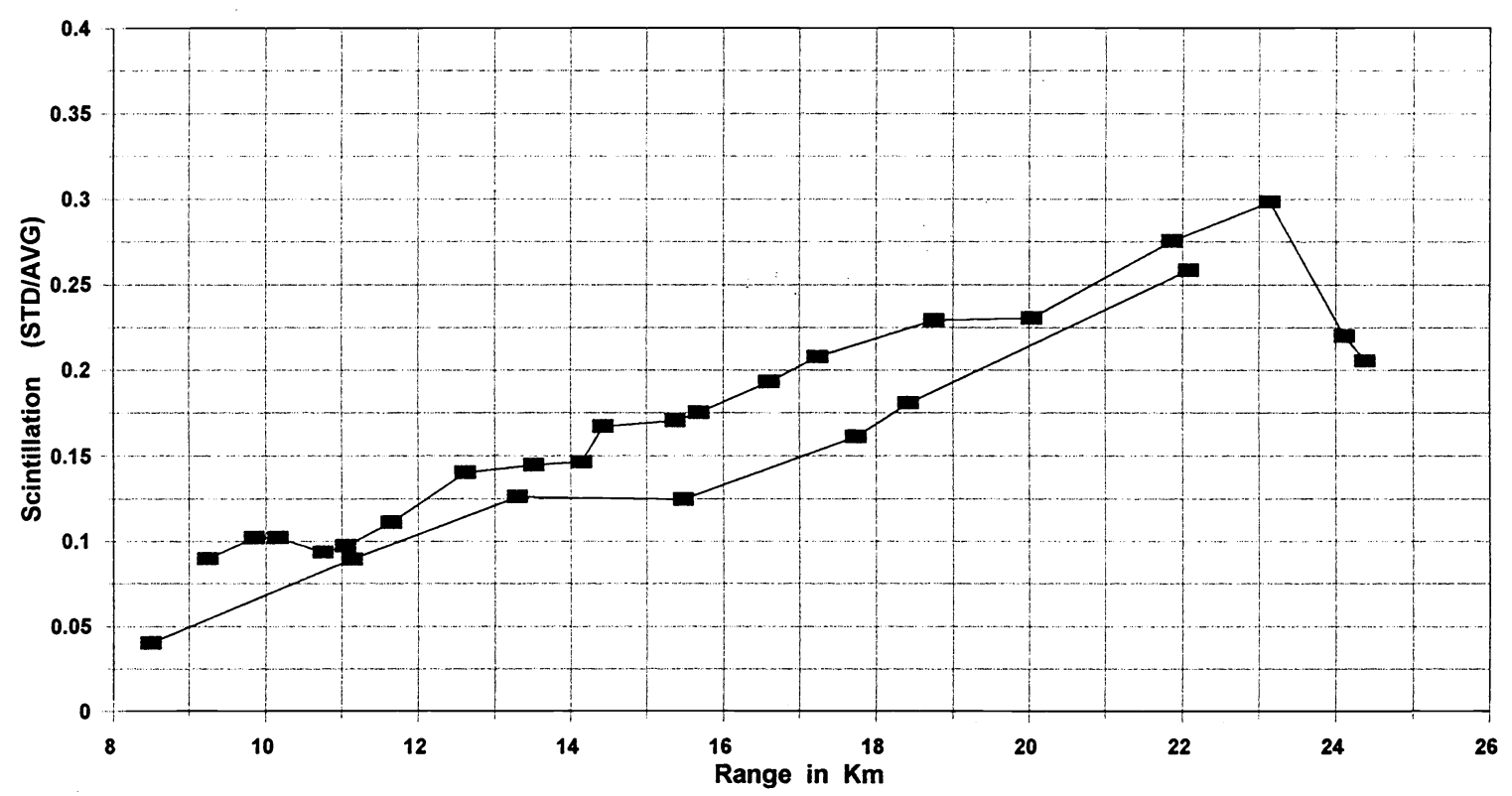

LAPTEX Scintillation 0.85 um

Outbound run 25 juli 1996

b

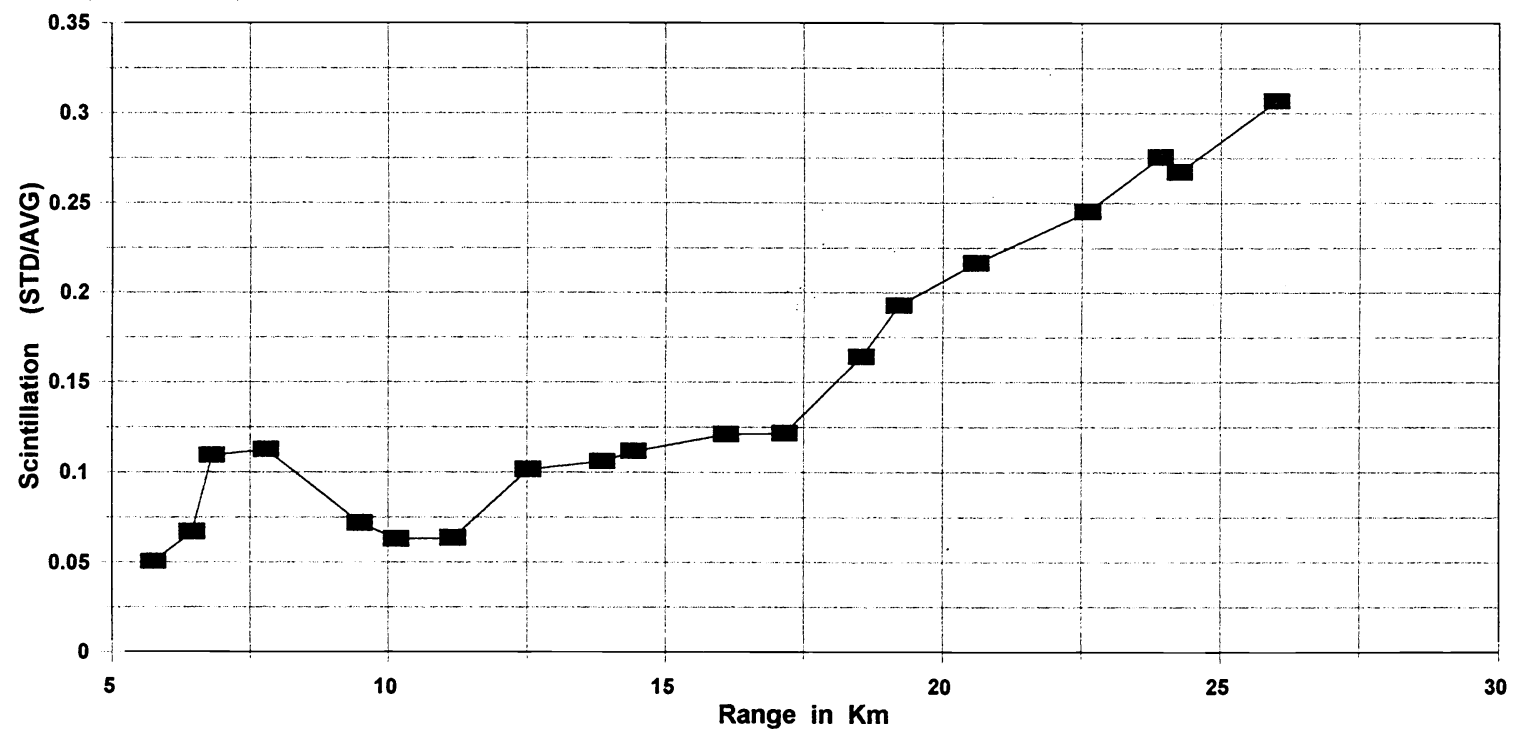

Figure 6: Scintillation vs range for $0.85 \mu \mathrm{m}, 1000 \mathrm{~Hz}$ source. 


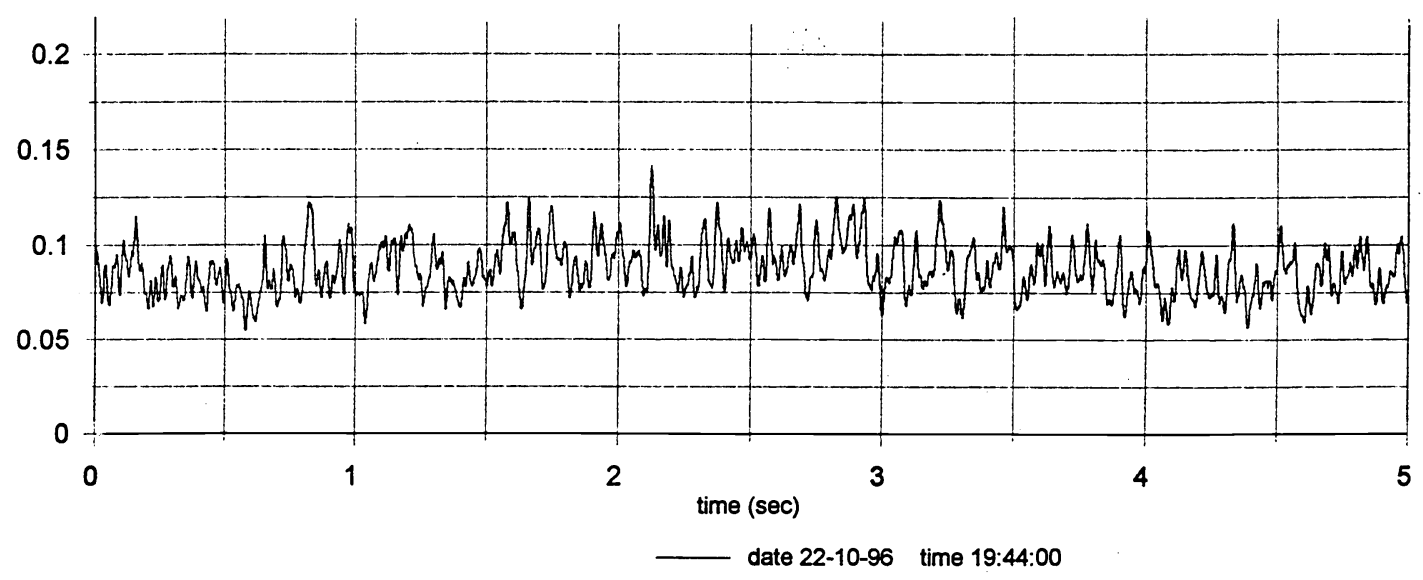

$\mathrm{b}$

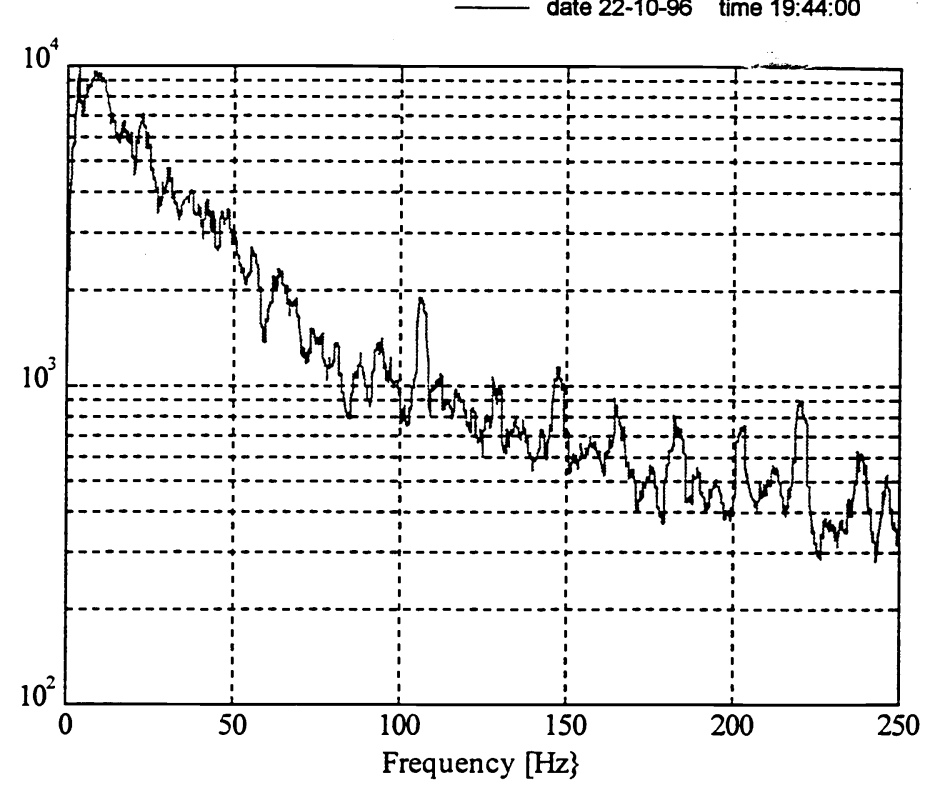

19.44

$(14 \mathrm{~km})$

c

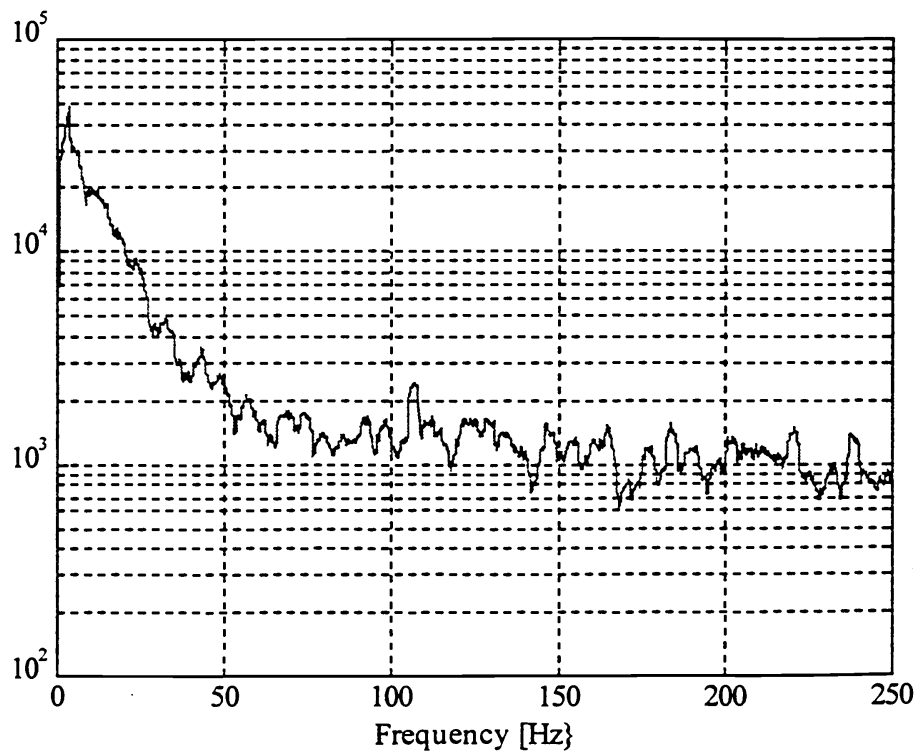

20.16

(24 km)

Figure 7: Example of time dependent signal (Figure 7a) and scintillation spectra at 2 ranges on 22 July, taken from $0.85 \mu \mathrm{m}$ setup. 


\section{$\underline{\text { 5. DISCUSSION }}$}

Figure 3a shows a predicted MW radiant curve, signicantly lower than the measured data for medium ranges of about $16 \mathrm{~km}$. For long ranges the measured and predicted data correspond well. Similarly for the $22^{\text {nd }}$ the measured data are 2 to 3 times higher for ranges from 17 to $27 \mathrm{~km}$. The reason for this effect is atmospheric refraction on that evening. For the morning of the $25^{\text {th }}$ the measured and predicted data correspond strikingly well, as shown in Figure 4a.

The LW measured and predicted data in Figure $4 \mathrm{~b}, \mathrm{c}$ show that the prediction on the average is about $30 \%$ less. It is not certain what the reason for this underestimation is. Both examples in Figures $4 a$ and $4 b, c$ show that the expected ranges for the MW and LW sensor correspond with the measurements. The MW sensor is apparently horizon limited.

The scintillation data in Figure 5 show the tendency to increase with range. The values of $(S T D / A V G)$ from $20 \mathrm{~km}$ of 0.2 to 0.4 indicate a non saturated situation, where the Rytov approximation for the wave deviations is still valid. The magnitude of the values do not correspond to the expected values from formula (3), probably due to the fact that $C_{N}^{2}$ is insufficiently known as function of height and as function of distance. Furthermore the prediction of $C_{N}^{2}$ values on the basis of Air to Sea Temperature Differences (ASTD), such as predicted by the bulk model of Kunz ${ }^{7}$ seems to be inaccurate as for various occasions the ASTD is zero along $90 \%$ of the path and still strong scintillation exists. It was also noted (see Table 3 ) that on the $17^{\text {th }}$ the buoy weather data at $1100 \mathrm{~m}$ deviate considerably from the long distance weather. Apparently a coastal effect influenced the weather at the buoy.

The scintillation data, obtained with the near IR transmission link, showed more accurately the behaviour of the phenomena with range. The horizon is somewhat closer as the source is mounted lower on the ship. It was found that the scintillation on the $22^{\text {nd }}$ just before the source was disappearing behind the horizon, tended to decrease, probably due to the fact that the lower air layer had less turbulence at that time (low wind speed, refractive condition with mirage).

The scintillation spectra of Figure 7 show the expected fall off of power with frequency, although the short range spectrum shows more power at frequencies between 50 and $100 \mathrm{~Hz}$ than that of $24 \mathrm{~km}$, where the beam grazes the sea surface.

\section{CONCLUSION}

The LAPTEX trial has shown to be an ideal opportunity to perform point target extinction measurements with range. The roughly measured detection ranges for the low altitude shipborne point target correspond well with the predicted by using the LOWTRAN7 transmission model. Most of the time the midwave measured data correspond well with the predicted curves. In some cases the prediction provides lower values due to refraction. The long wave prediction systematically underestimate the signal strength. The measurement methodology with a wide beam point source appeared to be correct. It is recommended however to use spectral band filters in the MW and LW sensors, which better correspond to the atmospheric transmission sub-windows. The scintillation data agree with results obtained during the EOPACE experiments ${ }^{4}$.

\section{ACKNOWLEDGEMENTS}

The Royal Nl Navy and the Office of Naval Research are greatly acknowledged for sponsoring the project. The Hellenic Navy is very kindly acknowledged for supporting the trials with their ships. All personnel of the NATO FORACS site greatly contributed to the success of the trial. Our colleagues Rob Kemp, Piet Schwering, Koos van den Ende, Ron de Haas and Marcel Moerman are acknowledged for their assistance during the experiments and the analysis of the data.

\section{REFERENCES}

1. A.N. de Jong; Testplan AC/243 (Panel 4/RSG.5) Low Altitude Point Target EXperiment, LAPTEX, 8-26 July 1996, NATO FORACS site, Crete, Greece, TNO report FEL-96-I195

2. Arie de Jong; Multispectral maritime background and clutter effects on small surface target detection, SPIE Proc 2742, Orlando, April 1996

3. D.L. Marable, Incorporation of Scintillation in Infrared Detection and Track Models for Low Altitude Targets in a Marine Environment, 1996 IRIS Conference on Targets, Backgrounds and Discrimination, January 30 - February 1, 1996

4. Arie de Jong; Low Elevation Transmission Measurements at EOPACE, Part III Scintillation Effects, SPIE Proc 3125, San Diego, 1997 
5. A.N. de Jong; LAPTEX point target data analysis, TNO report FEL-97-A067, March 1997

6. R.R. Beland; Propagation through Atmospheric Optical Turbulence, The IR and EO Systems Handbook, Vol 2 pp 157-232, SPIE Optical Engineering Press, 1993

7. G.J. Kunz; A bulk model to predict optical turbulence in the marine surface layer, TNO report FEL-96-A053, April 1996 